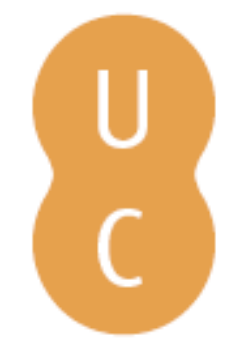

\title{
pommalina
}

\section{O terramoto no Haiti (12 de janeiro de 2010): análise na perspetiva da Medicina de catástrofe: do impacto à atualidade}

\begin{tabular}{|c|c|}
\hline Autor(es): & Araújo, Adriana; Campos, Paulo; Reis, Ana Mafalda; Bandeira, Romero \\
\hline Publicado por: & $\begin{array}{l}\text { Imprensa da Universidade de Coimbra; RISCOS - Associação } \\
\text { Portuguesa de Riscos, Prevenção e Segurança }\end{array}$ \\
\hline $\begin{array}{l}\text { URL } \\
\text { persistente: }\end{array}$ & URI:http://hdl.handle.net/10316.2/34955 \\
\hline DOI: & DOI:http://dx.doi.org/10.14195/978-989-96253-3-4_155 \\
\hline Accessed : & 26-Apr-2023 08:51:57 \\
\hline
\end{tabular}

A navegação consulta e descarregamento dos títulos inseridos nas Bibliotecas Digitais UC Digitalis, UC Pombalina e UC Impactum, pressupõem a aceitação plena e sem reservas dos Termos e Condições de Uso destas Bibliotecas Digitais, disponíveis em https://digitalis.uc.pt/pt-pt/termos.

Conforme exposto nos referidos Termos e Condições de Uso, o descarregamento de títulos de acesso restrito requer uma licença válida de autorização devendo o utilizador aceder ao(s) documento(s) a partir de um endereço de IP da instituição detentora da supramencionada licença.

Ao utilizador é apenas permitido o descarregamento para uso pessoal, pelo que o emprego do(s) título(s) descarregado(s) para outro fim, designadamente comercial, carece de autorização do respetivo autor ou editor da obra.

Na medida em que todas as obras da UC Digitalis se encontram protegidas pelo Código do Direito de Autor e Direitos Conexos e demais legislação aplicável, toda a cópia, parcial ou total, deste documento, nos casos em que é legalmente admitida, deverá conter ou fazer-se acompanhar por este aviso.

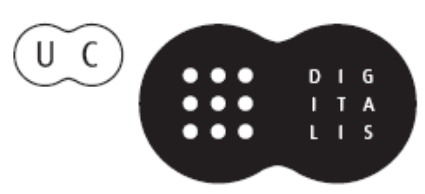



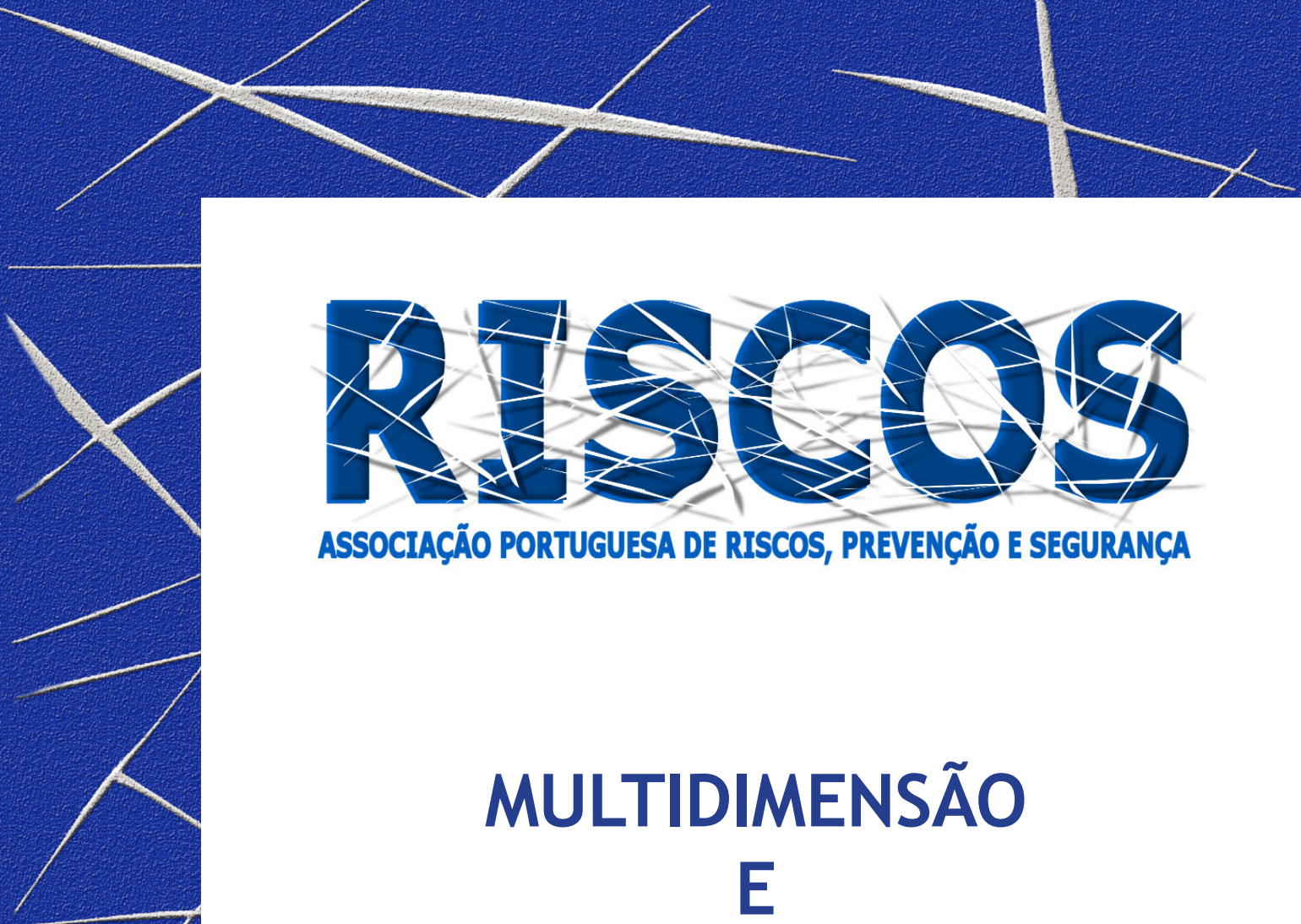

ASSOCIAÇÃO PORTUGUESA DE RISCOS, PREVENCCÃO E SEGURANÇA

MULTIDIMENSÃO

E
TERRITÓRIOS DE RISCO

III Congresso Internacional

I Simpósio Ibero-Americano

VIII Encontro Nacional de Riscos

Guimarães

2014 


\title{
O TERRAMOTO NO HAITI (12 DE JANEIRO DE 2010). ANÁLISE NA PERSPETIVA DA MEDICINA DE CATÁSTROFE: DO IMPACTO À ATUALIDADE
}

\author{
Adriana Araújo \\ Instituto de Ciências Biomédicas Abel Salazar, Universidade do Porto \\ adrianafilipaaraujo@gmail.com \\ Paulo Campos \\ Instituto de Ciências Biomédicas Abel Salazar, Universidade do Porto \\ pacampos@netcabo.pt / paulocampos@inem.pt \\ Ana Mafalda Reis \\ Instituto de Ciências Biomédicas Abel Salazar, Universidade do Porto \\ docmaf@sapo.pt \\ Romero Bandeira \\ Instituto de Ciências Biomédicas Abel Salazar, Universidade do Porto \\ hmedcat@icbas.up.pt
}

\begin{abstract}
RESUMO
A Medicina de Catástrofe é uma especialidade ou competência que preza pela sua atualidade, já que a ação humana avoluma a complexidade das condicionantes associadas aos fenómenos naturais, influenciando tanto a sua ocorrência como o seu poder destrutivo.

0 terramoto de 12 de Janeiro de 2010 no Haiti assolou aquele que era já classificado como o país menos desenvolvido do hemisfério ocidental, tendo ocorrido num contexto de excecional vulnerabilidade. Por todas as suas particularidades, esta megacatástrofe suscitou inúmeros desafios novos aos interventores, tornando-se um inestimável exemplo para extrapolar ensinamentos e criar melhores planos de atuação. A abordagem do desastre é realizada na perspetiva da Medicina de Catástrofe através da revisão de bibliografia de referência na área, artigos científicos, relatórios e comunicados de imprensa, incluindo uma discussão da intervenção humanitária de França e Portugal, baseada em entrevistas a intervenientes, nomeadamente ao Coronel e Médico-chefe da Força de Intervenção Aeromóvel Francesa Michel Orcel, e ao Comandante Elísio Oliveira e Dr. José Cunha da Cruz, ambos pertencentes ao Destacamento Português de Ação Humanitária.

Esta dissertação deverá servir como alerta para a importância da Medicina Preventiva e Preditiva e da melhoria da preparação dos profissionais de saúde para este tipo de intervenção, sendo premente fortalecer a capacidade de resposta às catástrofes.
\end{abstract}

Palavras-chave: medicina de catástrofe, vulnerabilidade, riscos, terramoto, Haiti

Introdução

\section{Conceitos e definições}

A noção de Medicina de Catástrofe surge-nos como uma prioridade numa emanação dos tempos que correm. Trata-se de uma nova especialidade ou de uma competência se assim the quisermos chamar. Propriamente será uma ação pluridisciplinar em que os conhecimentos do foro médico se interpenetram com outros de índole profundamente diferente, quer sejam de carácter Meteorológico ou Espeleológico (Bandeira, 2014).

De acordo com Bandeira (2014), o conceito de catástrofe muito para além da sua definição baseia-se nos componentes: afluxo intenso de vítimas, destruições de ordem material, desproporcionalidade acentuada entre os meios humanos e materiais de socorro e as vítimas a socorrer, simultaneidade. 


\section{Catástrofes Naturais}

Quando se fala em catástrofes naturais é necessário ter em conta a forte vertente antropocêntrica do conceito de catástrofe ou, de outra forma, tais eventos não passariam de fenómenos meteorológicos ou geológicos; considera-se, portanto, a sua interação sobre o Homem (Gunn, 1992; Braine, 2006; Bandeira, 2008; Herranz Araujo et al., 2010).

De acordo com o CRED, o número de catástrofes naturais relatadas a nível mundial aumentou exponencialmente desde o ano 1900 até 2000, verificando-se ainda um aumento do impacto económico e humano destes eventos entre 1975 e 2011 (EM-DAT, s/data), sendo os terramotos das hecatombes mais devastadoras dos últimos anos (Braine, 2006).

Uma avaliação nacional dos riscos associada à criação de mapas dos mesmos fornece os dados essenciais para o desenvolvimento informado de capacidades e aprimoramento das atividades tanto de prevenção como de preparação. A avaliação e cartografia dos riscos são os componentes centrais de um processo mais genérico, a gestão dos riscos, que ademais identifica as capacidades e recursos disponíveis para reduzir os níveis de risco identificados ou os possíveis efeitos duma catástrofe (análise das capacidades) e considera o planeamento de medidas apropriadas de mitigação dos riscos (planificação das capacidades), a monitorização e revisão dos perigos, riscos e vulnerabilidades, assim como a consulta e comunicação dos achados e resultados (European Comission, 2010).

\section{O terramoto no Haiti: 12 de Janeiro de 2010}

\section{Contextualização: o Haiti antes do terramoto}

As catástrofes tocam fundamental e profundamente os países mais desprovidos e a sua amplitude é inversamente proporcional à riqueza e à organização, particularmente no domínio médico, da região atingida (Kouchner, 1983; Braine, 2006; Bandeira, 2008).

O Haiti, já antes do terramoto de 2010, era classificado como o país menos desenvolvido do hemisfério ocidental (United Nations, 2010); a sua vulnerabilidade ambiental e fatores sociais como pobreza, instabilidade política, urbanização rápida, concentração de população (39\%) e recursos (66\% do PIB) na capital e a natureza frágil do Estado exacerbam as consequências dos fenómenos naturais (United Nations, 2002; Goyet et al., 2011), tendo sido neste contexto tão particular que ocorreu uma megacatástrofe de repercussões inéditas.

A toda esta vulnerabilidade acresce o facto de o país ser regularmente atingido por fenómenos naturais como inundações, deslizamentos de terra, tempestades, furacões, tsunamis e terramotos, refletindo-se numa tendência alarmante de catástrofes sucessivas (Rencoret et al., 2010; United Nations, 2010; Goyet et al., 2011).

\section{Características do terramoto}

No dia 12 de Janeiro de 2010, às 16h53 locais (21h53 UTC), um sismo de magnitude 7.0 assolou o Haiti. O seu hipocentro foi a $13 \mathrm{~km}$ de profundidade (USGS, 2010) e o epicentro a cerca de 25 $\mathrm{km}$ a sudoeste de Porto Príncipe, sobre a falha de Enriquillo- Plantain Garden (DesRoches et al., 2011).

\section{Impacto imediato}

Aextensão dos danos e perdas provocados por este sismo reflete a vulnerabilidade particularmente alta do Haiti. Embora a USGS tenha registado 22 terramotos de magnitude igual ou superior a 
7.0 em 2010, a quase totalidade das fatalidades foram devidas ao terramoto de 12 de Janeiro no Haiti: este foi responsável por mais de $98 \%$ das mortes derivadas de terramotos nesse ano (Goyet et al., 2011; USGS, 2011).

\section{A resposta}

\section{Os intervenientes}

Num contexto de catástrofe natural as autoridades nacionais estão encarregues de coordenar a resposta, o que foi especialmente problemático no Haiti, uma vez que o próprio governo se encontrava numa situação extremamente difícil (Grünewald et al., 2010).

\section{Fases da resposta}

As Nações Unidas consideram um ciclo de gestão de catástrofe, no âmbito do qual definem as suas atividades de resposta, e que se divide em três grandes categorias - fase de pré-emergência, fase de emergência e fase pós-emergência (United Nations, 2002).

\section{Intervenção humanitária em duas perspetivas: o papel de França e de Portugal}

\section{Comparação e discussão dos resultados}

Através dos testemunhos do Coronel e Médico-chefe da Força de Intervenção Aeromóvel Francesa Michel Orcel, do Comandante Elísio Oliveira - chefe da missão portuguesa no Haiti, e do Dr. José Cunha da Cruz - médico e chefe do Núcleo de Segurança e Saúde da Autoridade Nacional de Protecção Civil, extrai-se que, logo pelas dissemelhanças nos seus objetivos, as intervenções humanitárias dos dois países em questão foram francamente distintas.

Quanto aos resultados, conclui-se que a intervenção humanitária francesa teve um considerável impacto sanitário, com grande sucesso nas várias áreas de atuação. Embora os dados quantitativos da intervenção humanitária portuguesa sejam escassos, infere-se que pelo seu rápido acionamento e capacidade técnica foi um importante contributo para o alojamento e apoio de centenas de desalojados.

\section{O Haiti depois do terramoto: situação atual}

Dois anos depois do terramoto a ONU ressaltou que, apesar de ser importante priorizar o desenvolvimento a longo termo, a crise humanitária no Haiti não tinha terminado: mais de 500,000 pessoas estavam a habitar em campos provisórios, com a epidemia da cólera ainda a provocar mortes (OCHA, 2012).

\section{Reflexões finais}

A megacatástrofe ocorrida no Haiti em Janeiro de 2010 demonstrou à humanidade os efeitos devastadores que os fenómenos naturais podem ter, alertando para as consequências de uma má gestão dos riscos.

Muito além dos seus aspetos negativos, as catástrofes devem ser encaradas como fontes de aprendizagem. O seu estudo permite reforçar o conhecimento na área, contribuindo para uma evolução científica e tecnológica que, em última instância, beneficia as populações.

$\mathrm{O}$ caso do Haiti, pela sua singularidade, foi alvo de inúmeras diligências. 
Da comparação efetuada entre duas intervenções humanitárias concretas, pode-se eduzir que França teve um papel mais preponderante, prestando significativo apoio sanitário, enquanto Portugal teve um papel essencialmente social, podendo-se considerar ambas as intervenções bem-sucedidas.

É crucial aplicar as lições extrapoladas tanto na melhoria da prevenção como de intervenções futuras.

Finalmente, não deve ser olvidado o efeito devastador duma segunda catástrofe, sendo a situação atual do Haiti, 4 anos após o impacto, ilustrativa das dificuldades de recuperação.

\section{Bibliografia}

Allègre, C. (1993) - As Fúrias da Terra. Sousa, F. (trad) Lisboa, Relógio D’Água Editores

Bandeira, R. (2008) - Medicina de Catástrofe: Da Exemplificação Histórica à latroética. Porto, Universidade do Porto

Bandeira, R. (2014) - Medicina de Catástrofe - Sua Emergência e Especificidade como Medicina de Excepção. Sumário da Lição de Agregação, ICBAS/UP, Universidade do Porto

Braine, T. (2006) - Was 2005 the Year of Natural Disasters? Bulletin of the World Health Organization 84 (1): 1-80. Disponível em: http://www.who.int/bulletin/volumes/84/1/news10106/en/

DesRoches, R.; Comerio, M.; Eberhard, M.; Mooney, W.; Rix, G.J. (2011) - Overview of the 2010 Haiti Earthquake. Earthquake Spectra, 27 (S1): S1-S21

EM-DAT - Emergency Events Database (s/data) - Natural Disasters Trends. Disponível em: http://www.emdat. be/natural-disasters-trends

European Comission (2010) - Risk Assessment and Mapping Guidelines for Disaster Management. Brussels, European Comission

Goyet, C.deV.de; Sarmiento, JP.; Grünewald, F. (2011) - Health Response to the Earthquake in Haiti: January 2010. Washington D.C., Pan American Health Organization

Grünewald, F.; Renaudin, B. (2010) - Real-Time Evaluation of the Response to the Haiti Earthquake of 12 January 2010. Groupe URD

Gunn, S.A. (1992) - Le Médecin et les Catastrophes. Revue de l'Amelisap 13: 20-23

Herranz Araujo, P.; Gutiérrez Marco, J.C. (2010) - Desastres Naturales: Una Visión Crítica Sobre su Entendimiento y Gestión. Dendra Médica: Revista de Humanidades 9 (2): 162-175

Kouchner, B. (1983) - Epidemiologie. In: Médecins sans frontières (eds) Soins Urgents en Situations de Catastrophe. Paris, Hermann

OCHA - Office for Coordination of Humanitarian Affairs (2012) - Emergency Relief Coordinator's Key Messages on Haiti. Issue Number 22. United Nations

Rencoret, N.; Stoddard, A.; Haver, K.; Taylor, G.; Harvey, P. (2010) - Haiti Earthquake Response: Context Analysis. Active Learning Network for Accountability and Performance in humanitarian action (ALNAP); United Nations Evaluation Group (UNEG); Development Assistance Committee (DAC)-Network on Development Evaluation

United Nations (2002) - United Nations Response to Natural Disasters: Mandates, Roles and Mechanisms of UN Enteties in the Disaster Management Cycle

United Nations (18 February 2010) - Revised UN Humanitarian Appeal

USGS - United States Geologic Survey (2010) - PAGER - M 7.0 - HAITI REGION, Alert Version 1. Disponível em: http://earthquake.usgs.gov/earthquakes/pager/events/us/2010rja6/onepager.pdf

USGS - United States Geologic Survey (11 January 2011) - Haiti Dominates Earthquake Fatalities in 2010. USGS Newsroom. Disponível em: http://www.usgs.gov/newsroom/article.asp?ID=2679\#.U2y25_ldXng 